\title{
Juan Gálvez y Leandro Fernández de Moratín. Cuatro escenas, obra de Gálvez, inspiradas en las comedias de Moratín
}

\author{
Juan Martínez Cuesta *
}

\section{RESUMEN}

Este articulo analiza los cuatro lienzos ejecutados por Juan Gálvez (1774-1847) destinados a ilustrar la edición de las obras del dramaturgo

Leandro Fernández de Moratín, publicadas por la Real Academia de la Historia, en 1830. Juan Gálvez fue uno de los pintores de cámara en la Corte de Fernando VII, trabajando en distintos Reales Sitios. Fue director de la Real Academia de Bellas Artes de

San Fernando. Los cuatro lienzos citados constituyeron el modelo para las litografias de las siguientes obras de Moratin: 1) "El si de las niñas", acto III, escena XIII; 2) "La mojigata", acto II, escena II; 3) "La escuela de maridos", acto III, escena VII; 4) "El médico a palos", acto II, escena $V$.

\section{ABSTRACT}

This article describes the four canvas painted by Juan Gálvez (1774-1847) in order to illustrate the comedies written by Leandro Fernández of Moratin, published by the Royal Spanish Academy of History, in 1830. Juan Gálvez was one of the official painter in Ferdinand VIII's court, also he was director of the Royal Spanish Academy of Arts. The four canvas were models for litographies of Moratín's works: 1) "El si de las niñas", act III, scene XIII; 2) "La mojigata", act II, scene II; 3) "La escuela de maridos", act III, escena VII; 4) "El médico a palos", act II, scene $\mathrm{V}$.

* Este artículo es una publicación póstuma de nuestro compañero en la investigación de la Historia del Arte. Ha sido un honor para nuestra revista contar con la colaboración de Juan MARTÍNEZ CUESTA (1962-1999) a quien recordaremos con gratitud. 
El propósito de este artículo es presentar de forma íntegra un estudio que realicé sobre cuatro interesantes lienzos ejecutados por Juan Gálvez (1774-1847) inspirados en otras tantas comedias de Leandro Fernández de Moratín (1760-1828) y que figuraron en una exposición organizada conjuntamente por el Indianapolis Museum of Art y The Spanish Institute de Nueva York a finales de 1996 y principios del año siguiente. La muestra pretendia mostrar al público americano la gran riqueza y variedad de la pintura española del siglo XVIII y principios del XIX, cuya impronta viene marcada por la fuerte presencia de artistas extranjeros, en la primera parte de esta centuria, y la gran personalidad de Francisco de Goya que monopoliza su segunda mitad. Se buscaba equilibrar estos dos polos con la inclusión de obra de otros artistas contemporáneos demostrando su buen hacer, al tiempo que se hacia hincapié en lo desconocido que resulta este periodo de nuestra historia del arte fuera de nuestras fronteras. Este reto también se podría plantear dentro de nuestras fronteras, donde poco a poco, junto a la gran bibliografía que existe en torno a la figura del genial aragonés, empezamos a encontrar la relativa a otros pintores cuya importancia y calidad nos confirman que España vivió una nueva época de esplendor.

\section{JUAN GÁLVEZ Y SU ACTIVIDAD EN LA CORTE}

De entre los diferentes artistas que trabajaron junto a Vicente López en la Cámara del Rey don Fernando VII vamos a hablar de la labor del pintor Juan Gálvez. Nuestro artista nació en 1774 en la villa de Mora de Toledo y entró a trabajar al servicio de la Corte en 1794 gracias a un cuadro que presentó al Rey don Carlos IV. Sus primeros pasos los dio junto a Luis Japelli, con el que trabajó como ayudante en el techo que estaba realizando en la Casita del Príncipe del Real Sitio de El Escorial. Tan satisfecho quedó Su Majestad con su labor, que al año siguiente fue de nuevo llamado como ayudante de este mismo pintor en la decoración del techo de la Pieza de Retrete de la Casita del Príncipe del Real Sitio de EI Pardo.

Sus primeros encargos fueron la decoración de dos coches de gala con destino al servicio de la Reina, doña María Luisa de Parma, entre los años 1797 y 98 . Terminados estos trabajos, en 1801, pasó al Real Sitio de Aranjuez, donde bajo la dirección de Juan Duque, estuvo trabajando en la decoración de algunos techos del Palacio Real y de la Casa del Labrador. En 1806, siguiendo en su misma línea de ayudante, pasó a trabajar a las órdenes de Mariano Salvador Maella en la bóveda de la Sala de Billar de la Casita del Labrador, y junto a Luis Japelli, con la ejecucción de una medalla que representaba «Las Tres Gracias» para una de las bóvedas de este mismo palacete. 
Tras la Guerra de la Independencia, vuelve al servicio de la Corte en 1814, llamado por Fernando VII que le encarga la realización de un retrato al óleo, al tiempo que consigue el título de Académico de Mérito de la Real Academia de Bellas Artes de San Fernando. Por fin, tras la muerte de Luis Japelli pasó a ocupar la plaza de Pintor de Cámara, cargo que juró el 25 de agosto de 1816 en manos del Conde de la Puebla, Sumiller de Corps de S.M. Al igual que el resto de artistas de la Real Cámara, nuestro pintor puso todo su ingenio en los trabajos de preparación del Real Cuarto de la segunda esposa del Rey.

La obra más importante que se acometió fue la decoración de las sobrepuertas de la pieza utilizada como Tocador, donde bajo la dirección de Vicente López se ejecutaron seis enormes lienzos en la técnica de grisalla. En este encargo también trabajó Goya, siendo su última actuación como Pintor de Cámara, con el maravilloso cuadro de "Santa Isabel atendiendo a un enfermo", que, aunque ya no in situ, todavía se conserva en el Palacio Real. Juan Gálvez tuvo una participación muy amplia, aunque se podria considerar un tanto secundaria, ya que se encargó de la decoración de uno de los trascuartos ("Los techos de la nueva habitación de trascuarto de la Reina... en cuya habitación pintó 12 techos incluidos el de los alfeizares de las ventanas y acompañando las caídas de los mismos alfeizares") -cuyo trabajo no ha llegado hasta nuestros días-, la ejecución de un trampantojo en la Cámara Gasparini ("También pintó imitando al bordado de la colgadura de la pieza de la cámara llamada Gasparini, los huecos que ocupaban los sobre espejos y aumento de las cortinas de la misma pieza, correspondientes a la colgadura") y la restauración de la Escalera Principal («Posteriormente le fue encargado el limpiar y restaurar las pinturas al fresco de la escalera principal y reforzar nuevamente todas las tintas de la misma"). $Y$, por último, también por este mismo motivo realizó el diseño del Arco para la ceremonia de la Entrada Pública de doña María Isabel de Braganza en Madrid.

Su actividad en la Corte fue amplísima quedando cumplida prueba en todos los Reales Sitios de su prolífica creatividad, al igual que en el Casino de la Reina. También desarrolió una importante labor en la Real Academia de Bellas Artes, donde llegó a ser nombrado Director el nueve de noviembre de 1829, y Director General, el dieciséis de enero de 1838, quizás como reconocimiento a su trabajo, tanto en este instituto como en la Casa Real, pues a finales de 1835 ya habia sido cesado. Juan Gálvez murió el 12 de diciembre de 1846 dejando siete hijos, entre los que destacó Miguel que trabajó como arquitecto para la Reina Gobernadora en la posesión de Quitapesares, cerca del Real Sitio de La Granja. 


\section{OTRAS EMPRESAS ARTISTICAS DE GÁLVEZ:}

\section{a. La Ruinas de Zaragoza:}

Pero al margen de su labor como pintor al servicio del Rey, Gálvez también destacó en su labor de ilustrador creando obras para ser estampadas en la Real Calcografía. Hasta el momento la obra más conocida de su mano es la famosa serie que realizó junto a Fernando Brambilla sobre las "Ruinas de Zaragoza» y que fue publicada en la ciudad de Cádiz, en 1812, bajo la protección de la Real Academia de Bellas Artes de esa ciudad. El trabajo está formado por treinta y seis estampas de diferentes tamaños que muestran los estragos que sufrió la ciudad aragonesa durante la invasión francesa. "Doce grandes de a pliego, representan el estrago causado por las bombas en los principales edificios de la ciudad; otras doce medianas, ruinas de diferente género; en fin, doce más pequeñas serán retratos de los patriotas más señalados en aquella defensa, sacados del natural, con el traje y armas que heroicamente usaban, y puestos en acción en las lances que más nombres les dieron".

La colección de estampas se realizó gracias a la iniciativa del general Palafox, que tras el primer asedio de la ciudad de Zaragoza, en octubre de 1808 , solicitó la presencia de algunos artistas para que perpetuasen con sus pinceles los estragos causados por los invasores. A la llamada del militar no sólo acudió Gálvez acompañado por Fernando Brambilla, sino el mismo Francisco de Goya, pero su labor se vio interrumpida por el inicio del segundo sitio de la ciudad. A pesar de lo precipitado de su salida, ambos artistas, Gálvez y Brambilla, pudieron trasladar todo el material documental reunido a Madrid, lo que les permitió empezar a grabar las estampas de lo que iba a ser esta serie a partir del mes de noviembre de ese mismo año, 1808. Pero la presencia de las tropas enemigas en la capital, les obligó a ponerse a salvo, esta vez en Cádiz, lugar donde, como hemos dicho, lograron completar este ambicioso proyecto.

La serie no se empezó a publicar hasta 1812 y se dividió en doce entregas que se realizaron al final de cada mes. Cada entrega consistió en tres láminas de diferente tamaño, como se menciona en el título, hasta completar las treinta y seis. Por el momento se han localizado algunos dibujos de esta serie guardados por la Biblioteca Nacional y la Fundación Lázaro Galdiano. También se conservan determinadas planchas en la Calcografía Nacional —que fueron compradas por el Estado en 1956con las que en 1926 el Marqués de Rubí hizo una cuidada edición bajo el título de "Colección de Aguafuertes Grabados por Francisco Brambilla y Juan Gálvez 1791-1814 (Primera Carpeta)». La obra presentaba un total 
de ocho estampas de las que sólo cuatro pertenecian a la serie de Ruinas de Zaragoza.

\section{b. Las obras completas de Leandro Fernández de Moratín:}

La siguiente empresa artística de gran relevancia en la que se embarcó Gálvez fue la publicación de las obras teatrales de don Leandro Fernández de Moratín, trabajo que se realizó en 1830. la empresa fue acometida por la Real Academia de la Historia que tras la celebración de diferentes sesiones, a mediados de 1829, decidió que la edición debería de ir acompañada de algunas ilustraciones al igual que una estampa alegórica que encabezara la obra con un retrato del autor. En un principio se pensó hacer una tirada de tres mil ejemplares con papeles de diferentes calidades, de los que mil quinientos ejemplares llevarian incluidas las ilustraciones, aunque al final se redujo a dos mil, con papel de diferente calidad, siguiendo las mismas pautas. Parece ser que de esta forma la Academia cumplía un íntimo deseo de Fernando VII pues con esta impresión se quería emular la edición moratiniana realizada en Paris en 1825.

Así se explica en la introducción:

"En el año 1825 se hizo en Paris una edición de las obras dramáticas y liricas del célebre poeta $D$. Leandro Fernández de Moratín, que impresas antes en varios lugares, tiempos y tamaños, andaban sueltas y no siempre fielmente impresas, en manos de los estudiosos. Esta edición, reconocida como legítima por el autor, y publicada poco antes de su fallecimiento, proporcionaba a los extranjeros la facilidad de gozar de su lectura, al mismo tiempo que los españoles privados de esta ventaja por la ley que prohíbe la introducción de obras castellas impresas fuera del reino, carecian de la utilidad que para su mayor ilustración ofrecia la reunión de producciones tan apreciables.

Esta poderosa consideración fomentó en la Real Academia de la Historia, primero el deseo, y después el designio de publicar una colección de las obras de Moratín. Comprendió igualmente la Academia que una edición completa y esmerada de ella era el monumento inás digno que podía consagrarse a la fama póstuma de su autor; y que con ella, al paso que se miraba por la utilidad del público español, se daba también a las demás naciones una prueba de que nuestra Patria no se olvida de honrar la memoria de los hijos que la ilustran y ennoblecen".

El ocho de junio de 1829 se publicó la Real Orden por la que se daba licencia a la Real Academia de la Historia para que procediera a la publicación y unos días después la comisión, encabezada por los señores Musso y Miñano, pedia al Primer Pintor de Cámara, Vicente López, que 
realizara el "pensamiento de la portada" o estampa alegórica del frontispicio. Al tiempo que otros artistas, también cercanos a la órbita de la Cámara, se encargaban de realizar el resto de los diseños. El primero en responder al encargo fue José Ribelles que ejecutó las ilustraciones de las comedias «El Viejo y la Niña» y «El Barón», siguió José de Madrazo, que presentó su trabajo sobre Hamlet. A pesar de las dificultades económicas del Real Establecimiento Litográfico, que estuvieron a punto de paralizar los trabajos, la Academia no cejó en su celo de ver terminada su empresa en el menor tiempo posible, por lo que no dudó en presentar sus quejas ante el Monarca, denunciando la actitud de los jefes de este establecimiento. El último artista en concurrir al encargo fue Juan Gálvez que el cinco de marzo de 1830, presentaba el dibujo que serviria de ilustración a «El Médico a Palos».

A pesar de la lentitud con que se iba procediendo, la Real Academia, en la sesión celebrada el veintiuno de mayo de 1830, decidió ampliar la edición de cuatro a seis volúmenes para así poder incluir toda la obra de Moratín, tanto en verso como en prosa.

"Para desempeñar la empresa de un modo correspondiente a su objeto, a la honrosa aprobación del Soberano, a la ilustración de nuestros tiempos y al buen nombre de la Academia trató ésta desde luego reunir todas las obras de Moratin de que tenia noticia, tanto en verso como en prosa, tanto impresas como manuscritas. De todas ha formado una colección, en cuya parte lirica ha incluido no sólo varias composiciones conocidas anteriormente del público, y que los aficionados a Moratín echaban de menos en la edición de 1825, sino también otras inéditas que se conservan entre los papeles de los curiosos y que no desmerecen de las restantes. Entre ellas las hay de mérito muy sobresaliente, que prueban con cuánta modestia opinaba Moratín de si mismo, cuando manifestaba que su vena estaba destinada exclusivamente al género dramático».

Por fin, el veintiuno de agosto de 1830, la Academia pudo presentar a Fernando VII el primer volumen, dividido en dos tomos. Alertado de la prisa que corría terminar este trabajo, el ocho de octubre de este mismo año, Juan Gálvez presentó el resto de su trabajo, tres cuadros pintados al óleo, que servirian para "El Sí de la Niñas", "La Mojigata» y "La Escuela de Maridos".

El veintiuno de enero de 1831 la comisión dio por terminado el tomo II, también formado por dos volúmenes, en el que se reunieron todas las comedias originales de Moratín. El veinticinco de marzo ya estaba preparado todo el material necesario para proceder a imprimir el tercer tomo con el texto de las obras teatrales traducidas en el que se incluian dos estampas de Gálvez, de las comedias de Moliere, junto a la presentada por José 
Madrazo sobre "Hamlet". El cuarto tomo quedó ultimado el ocho de julio, de ese mismo año, cuando el joven Federico de Madrazo presentó su singular ilustración sobre la "Toma de Granada", completándose así los seis volúmenes. Tras diferentes consultas se decidieron fijar los precios de los ejemplares, según las calidades, en 168 reales - papel fino con estampas-, 144 reales - papel fino sin estampas-, 130 reales --papel común con estampas - y 108 reales - papel común sin estampas-.

Según se desprende de lo dicho, en un principio la edición iba a contar con una sola obra de Juan Gálvez que a tal efecto entregó ("presentó el dibujo correspondiente a la comedia El Médico a palos"). Tras la decisión de ampliar la edición, nuestro artista recibió un nuevo encargo, esta vez de tres obras, que ejecuta en un tiempo récord - del mes de mayo al mes de octubre-, pero esta vez ejecutadas en óleo sobre lienzo. Es decir, primero hubo un dibujo y luego tres lienzos, algo que es un tan singular si tenemos en cuenta que se trata para ser litografiados. Juan Gálvez, buen conocedor de esta técnica, sabía que el mejor original que se podía mandar para ser reproducido en grabado era un óleo porque así se facilitaba la interpretación de los colores en su traducción al blanco y negro.

La primera estampa ejecutada fue la de "El Médico a Palos", realizada por Juan Antonio López tomando como modelo el ya mencionado dibujo. La Academia quedó contenta con el resultado de la ilustración. Cabe pensar la idea que Gálvez, animado por las buenas críticas recibidas por su trabajo, presentara el dibujo transformado en pintura cuando recibió la segunda comisión por si había posibilidad de mejorar la obra, pero no fue así. Por eso si comparamos el lienzo con la estampa podemos observar pequeñas diferencias entre las dos, ya que el artista introdujo unas leves diferencias como las posturas de las manos, el sombrero caído en el suelo e incluso en la vestimenta de los personajes que aparecen en segundo plano. Pero tales menudencias pasaron inadvertidas para la comisión, ya que en el cuarto tomo, donde se incluye una descripción de las ilustraciones, hablando de esta escena se dice que "el original fue pintado por el mismo profesor D. Juan Gálvez", por lo que pienso que el lienzo tuvo que ser realizado al tiempo que los otros, a mediados de 1831.

Pero otras desavenencias ocurridas durante la realización de esta edición obligó a la Academia con contar con diferentes litógrafos. El primer trabajo de Juan Gálvez fue ejecutado por Juan Antonio López y los tres restantes por Alejandro Blanco. Merece la pena detener nuestra atención sobre los cuadros, observar las diferencias que existen entre las pinturas y sus versiones litográficas y advertir las diferencias de estilo que existen entre ambos los artífices que trabajaron las piedras. Por un lazo, Antonio 
López, un auténtico maestro litógrafo, hábil en el uso del lápiz litográfico que busca el predominio de los volúmenes disimulando al máximo las líneas y buscando superficies entonadas; frente a Alejandro Blanco, consumado grabador a buril acostumbrado a hacer incisiones sobre el cobre por lo que utiliza el trazo con el predominio de la línea como si de un grabado se tratara.

La edición de las obras de Moratín se puede considerar como la última gran empresa bibliófila de la España llustrada, que junto con la edición del Quijote de 1819, se llevó a cabo por la Real Academia de la Historia ya iniciado el siglo XIX. La elección de Gálvez y Ribelles para la invención de las ilustraciones fue un acierto pleno ya que sus composiciones supieron captar todo el espíritu moratiniano de las comedias, mundo nada ajeno a su formación dieciochesca. También estos detalles nos hablan de los gustos conservadores de la Corte, tan avanzado el siglo XIX, ya que no estamos ante una escena de las llamadas "de casaca" o recreación del ambiente de finales de la centuria anterior, sino de la interpretación de un tema literario casi coetáneo con el artista, aunque tratado con todo el con. vencionalismo típico de la decadencia de este momento. Tanto la mesura de las figuras como su colorido se ajustan perfectamente al mundo literario que están interpretando. El resultado es completamente diferente a las ilustraciones de la edición francesa, impresa en París en 1825, que adolecen de la frescura y sabor hispano que tan genialmente supieron captar los pintores españoles.

Pasamos ahora a describir cada uno de los cuadros, localizando el pasaje exacto de la comedia que ha servido de modelo.

\section{EL SI DE LAS NIÑAS}

Acto III, Escena XIII.

Comedia en tres actos estrenada en Madrid, en el Teatro de la Cruz, el 24 de enero de 1806.

Litografiada por Alejandro Blanco.

El cuadro presenta el momento cumbre de la obra, cuando don Diego perdona a su sobrino, don Carlos, y le da su consentimiento para que se case con doña Francisca. En la misma escena vemos a la madre de la joven, doña Irene, y a la criada Rita. Siguiendo las indicaciones dadas por el autor, Gálvez situó a los personajes en una sala de paso, con dos puertas a cada lado, de las que sólo vemos un par, y al fondo una escalera, que queda insinuada por la barandilla, que conduce al piso bajo de la posada. Los personajes van vestidos a la moda de principios 
Juan Gálvez y Leandro Fernández de Moratín. Cuatro escenas, obra de Gálvez...

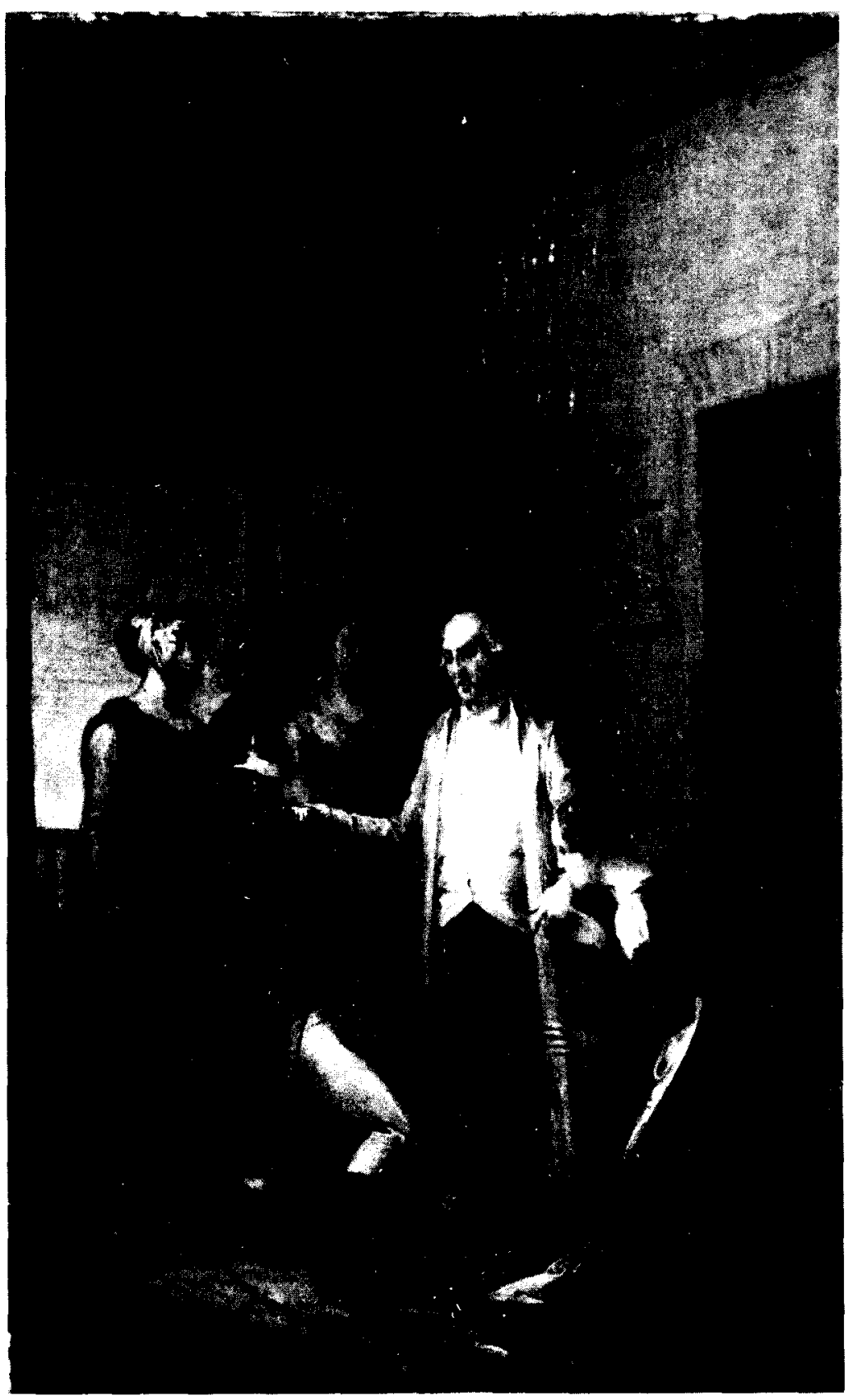


del siglo XIX, las damas con basquillas y abrigadas con mantillas que se quitan cuando entran en escena; mientras que don Diego presenta una chupa de faldones largos, algo en desuso en este momento y típica de las personas mayores apegadas a las tradiciones. $Y$ por último don Carlos, que por su condición de oficial, viste ropa militar, con altas botas y chaqueta con hombreras doradas y cuello alto que denota su graduación de teniente coronel "efectivo". La composición parece seguir la estampña que se presentó en la edición de esta obra, en 1806, por Pedro Vicente Rodríguez.

La obra alcanza su clímax cuando el anciano comprende cuán arrogante habia sido su comportamiento por haber concertado su matrimonio con una joven gracias al poder que le da el dinero, cuando de forma casual descubre que ella está enamorada de otro joven que resulta ser su sobrino. La bondad de don Carlos le lleva a abrir su corazón y exclamar:

- «Aquí no hay escándalos... Ése es de quien su hija está enamorada... Separarlos y matarlos viene a ser lo mismo... Carlos... No importa... Abraza a tu mujer".

Para acabar más adelante concluyendo:

- «Él y su hija de usted estaban locos de amor, mientras usted y las tías fundaban castillos en el aire, y me llenaban la cabeza de ilusiones, que han desaparecido como un sueño... Esto reculta del abuso de autoridad, de la opresión que la juventud padece; éstas son las seguridades que dan los padres y los tutores, y esto lo que se debe fiar en el sí de las niñas... Por una casualidad he sabido a tiempo el error en que estaba... ¡Ay de aquellos que lo saben tarde! ».

El Sí de las Niñas está considerada como la obra más famosa de Moratín y la más aplaudida por el público madrileño, desde el momento de su estreno hasta su retirada de la escena con motivo de la llegada de la Cuaresma. Fueron veintiséis días en que el Teatro de la Cruz registró un lleno debido al interés del público por presenciar la obra. Sin lugar a dudas, los actores que trabajaron en los papeles, dirigidos por el propio autor, también contribuyeron a su éxito. Como doña Irene actuó María Rivera, que según palabras del propio Moratín resultó «inimitable por su naturalidad y gracia cómica", como doña Francisca estuvo Josefa Ving y en el papel de don Diego, Antonio Prieto, "nuevo entonces en los teatros de Madrid, (y con esta obra) adquirió el concepto de actor inteligente, que hoy sostiene todavía con general aceptación».

La obra fue enseguida representada por toda España, tanto en teatros públicos como en casas particulares, siendo tal el interés en leerla 
que sólo en 1806 se hicieron cuatro ediciones del texto. Pero tan importante éxito tuvo una fuerte repercusión negativa entre las clases más conservadoras de la sociedad que se tradujo en continuas denuncias al Santo Oficio por una comedia que aparecía como anticlerical y contraria a las más honestas costumbres de la familia tradicional. Al final, gracias a la directa intervención del Príncipe de la Paz se pudo mantener la obra en cartelera. "Su respeto contuvo el furor de los ignorantes y malvados hipócritas; que no atreviéndose por entonces a moverse, remitieron su venganza para ocasión más favorable».

\section{LA MOJIGATA}

Acto II, Escena II.

Comedia en tres actos.

Litografiada por Alejandro Blanco.

Obra estrenada el 19 de mayo de 1804 en el Teatro de la Cruz de Madrid por la compañía de cómicos de este mismo local. A pesar de la rivalidad existente entre los diferentes teatros madrileños, el público se comportó con gran corrección hasta tal punto que "no hubo parcialidades, ni venganzas, ni conspiración, ni alboroto". Y esto parece ser que asi fue por el gran prestigio de Moratín, cuyo nombre bajo el título de una comedia era garantía de su éxito.

La comedia fue escrita hacia 1791, momento en que parece ser que empezaron a verse copias del texto. La obra fue concebida en su inicio como una pieza de teatro de cámara para ser representada en casas particulares y por aficionados como ocurrió en casa del abogado Pérez de Castro o en el palacio de la Marquesa de Santiago. También se sabe que el texto se conocía fuera de Madrid, y que más de una compañía se vio tentada a estrenar públicamente la obra. Quizás, esto motivó que unos años después el mismo Moratín retomara el argumento y decidiera fijar el texto, el cual parece que sufrió importantes alteraciones, al tiempo que eliminaba errores, tanto propios, como ajenos, que habían viciado la comedia. El afán de perfeccionamiento del autor le llevaba a revisar una y otra vez todos sus textos.

El argumento es una sagaz crítica al eterno vicio de la hipocresía, en la misma línea marcada por Tirso de Molina en "Marta la piadosa". La acción transcurre en Toledo, donde nos encontramos con don Claudio, caballero de Ocaña y joven petimetre de moda, que se dispone a desposar a doña Inés. Al tiempo aparece doña Claudia, prima de doña Inés, que inducida por su padre, don Martín, parece deseosa de abrazar 


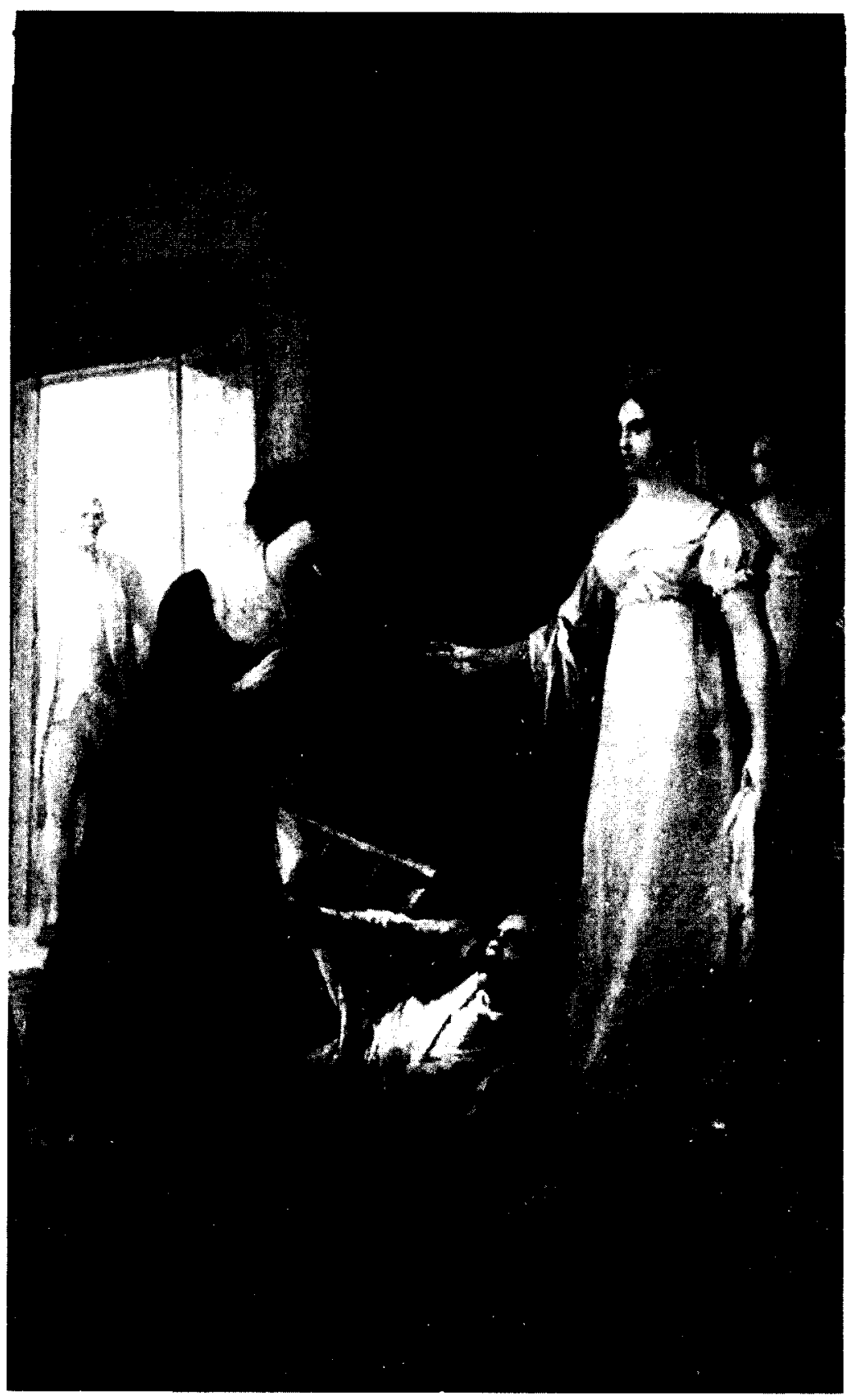


la vida religiosa. El enredo comienza cuando Perico, cirado de don Claudio, aconseja a su amo a que enamore a doña Claudia, ésta presa de cupido, decide urdir un plan para poder huir con su caballero y no reconocer la falsedad de su vocación. Al final se descubre todo el embrollo, siendo doña Inés quien toma los hábitos, mientras que los amantes reconocen sus engaños y logran el permiso paternal para contraer matrimonio, dejando de lado la filosofía del hipócrita: «En el mundo, el que no engaña no medra».

El elenco del teatro fue muy aclamado, sobre todo a Josefa Ving, en su papel de la Mojigata o gatamusa - antigua palabra castellana con la que se describía el momento en que el gato se agachaba o humillaba para después arañar y por extensión aplicable al "disimulado vellaco". La aclamada actriz, famosa por su gran flexibilidad, parece que dio al personaje de doña Clara, que representa al hipócrita, todo el descaro, falta de devoción y anhelo de libertad que había pretendido Moratín. También destacó Francisco López en el breve del tío Juan, demandadero de un convento, que según la crítica "pintó con excelencia un viejecillo tan pusilánime, inepto, encogido, frío, memo y ñoño como el autor lo imaginó".

La escena transcurre en casa de don Luis, padre de doña Inés, durante la hora de la siesta. Gálvez hace caso omiso a las indiciaciones que aparecen en el texto sobre como debía de aparecer el escenario y asi vemos que la acción se desarrolla en una sala de paso, con adornos que indican que estamos en la casa de una familia acomodada. Al fondo vemos una mesa sobre la que descansa un reloj; en los laterales, dos puertas, una a la derecha, que corresponde a la de la calle, y la de la izquierda que da a las habitaciones privadas de la mansión. En el foro, otra puerta, ésta corresponde a la habitación de don Clá dio, y dos ventanas.

El cuadro describe el momento, durante la siesta, en que don Claudio está enamorando a doña Clara y son advertidos por Lucía, criada de la dama, que alguien se acerca. El joven, llevado por los nervios y debido a la oscuridad que reina en la sala, tropieza con una silla y cae al suelo, haciendo un gran ruido. En este justo instante, aparece en escena doña Inés, que en el cuadro la vemos al fondo, y don Martín abre una de las ventanas para ver que está ocurriendo. La mojigata, haciendo acopio de toda su hipocresía, acusa a su prima de haberla sorprendido con don Claudio para así evitar que se descubran sus inclinaciones amorosas. 


\title{
3. LA ESCUELA DE MARIDOS
}

\author{
Acto III, Escena VII.
}

Comedia en tres actos.

\section{Litografiada por Alejandro Blanco.}

Obra estrenada en Madrid, el 17 de marzo de 1812, en el Teatro del Príncipe. Según parece la comedia fue escrita en 1808, año de la invasión napoleónica de la península, por lo que no se pudo representar hasta unos años después. Moratín formó parte del equipo español que respaldaron al gobierno instruso desde su cargo como secretario de la Interpretación de Lenguas y bibliotecario mayor de la Biblioteca Real, nombramiento que recibió en 1811. Los papeles principales se repartieron entre Eugenio Cristiani, que hizo de don Gregorio "con toda la expresión y movimiento cómico que requiere aquel ridículo personaje",. Josefa Ving y el gran Isidro Maiquez, considerado en su época como el mejor actor español de todos los tiempos. Con esta representación el autor declaraba sin ningún tipo de ambages su apoyo al Rey José Bonaparte, al tiempo que se convertía en todo un homenaje a los invasores por tratarse de la traducción de una obra de Jeán Baptiste Molière, "L'Ecole des maris", representada por primera vez en París, el 24 de junio de 1661, en el teatro del Palais-Royal.

El argumento de la comedia no era ajeno al público español, pues parece que el mismo comediógrafo francés se inspiró en "La discreta enamorada" de Lope de Vega. Los personajes centrales, el tutor estúpido, incrédulo, lleno de perjuicios y de severidades inoportunas y excesivas, y su joven pupila cándida y enamorada ya habían sido utilizados por Pierre-Augustin Caron de Beaumarchais, en «Le Barbier de Séville" (El Barbero de Sevilla) -obra estrenada el 23 de febrero de 1775, y que en 1816 fue convertida en ópera por Gioacchino Rossini, bajo este mismo título «ll Barbiere di Siviglia»-.

El argumento consiste en la presentación de dos modelos de educación femenina encargados por sus tutores. Por un lado don Manuel, tutor de doña Leonor, liberal y de carácter mundano, frente a don Gregorio y su protegida, doña Rosa, la cual mantiene encerrada en su casa. (Caracteres que en la obra de Moliére son encarnados por Aristo y Leonor, y Sganarelle e Isabel respectivamente). El enredo se forma en torno a don Gregorio que hábilmente es utilizado por Rosita para que de forma desesperada comunique a su esforzado amante, don Enrique, la cruel situación en la que vive confinada en su casa y su mísero destino por estar apalabrada para contraer matrimonio con su anciano tutor. La obra alcanza su clímax cuando la joven haciéndose pasar por Leonor 
Juan Gálvez y Leandro Fernández de Moratín. Cuatro escenas, obra de Gálvez...

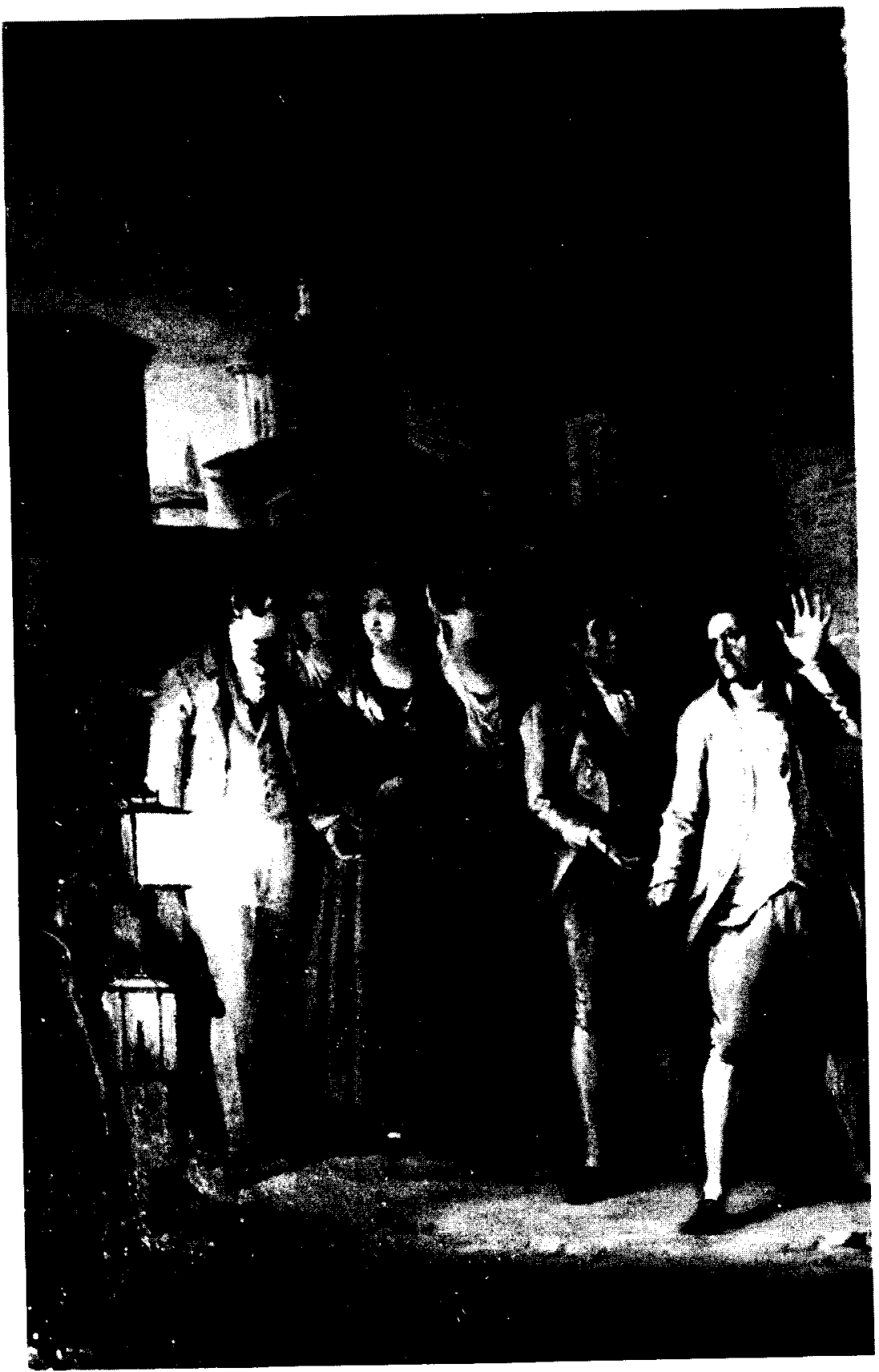


escapa de su casa para encontrar refugio en la de su pretendiente. Y éste es el momento escogido por Gálvez en el cuadro, cuando el pobre don Gregorio descubre el engaño y no le queda más remedio que autorizar, contra su voluntad, el enlace de ambos jóvenes para evitar un escándalo.

En primer plano vemos a ambos ancianos discutiendo, primero don Gregorio, con la mano izquierda levantada y la derecha cerrada, pues se supone que en ella guarda la llave de su hogar, que en un singular descuido, ha dejado abierto, permitiendo la salida de Rosa. Tras él su hermano, don Manuel, que con gesto conciliador, intenta hacerle comprender que ha sido él mismo quien ha provocado esta situación. Pero no hay forma, por lo que no se produce la deseada reconciliación. Siguiendo las indicaciones del autor, los personajes van vestidos de formas diferentes para hacernos ver la diferencia de caracteres. Así, el primer tutor, al igual que sus anticuados métodos, va tocado con un sombrero de tres picos, y viste un chaleco largo y chupa, frente a su hermano que cubre la cabeza con un sombrero de copa y se abriga con una levita. Tras ellos el resto de los personajes, don Enrique junto a su amada Rosa, seguidos por Leonor - ambas mujeres son también hermanas - y Juliana, su criada, para completar el grupo Cosme, criado de don Enrique, el comisario, el escribano y el mozo que porta la linterna que ilumina la escena. Un total de diez personajes, los mismos que figuran en esta escena, la última del tercer acto.

Los hechos están ambientados en la Plazuela de los Afligidos, castizo lugar formado por la confluencia de las calles de San Bernardino y de Leganitos, donde ambos ancianos vivian con sus respectivas pupilas. La acción se inicia hacia las cinco de la tarde, para terminar a las ocho, cuando empieza a anochecer, tal y como el pintor ha reflejado en su obra. Al fondo se distingue la antigua iglesia de los Afligidos, convertida en ruinas cuando Gálvez realizó el cuadro. El edificio religioso fue fundado en 1611 por la orden de los Premonstratenses, aunque el perfil que distinguimos en el fondo de la composición corresponde al templo levantado por Ventura Rodríguez en 1776. La fábrica tenía forma de cruz griega y estaba coronada por una esbelta cúpula centralizada. La única descripción que conocemos en su interior se la debemos a Antonio Ponz, dice así: «El altar mayor debe numerarse entre los disparates de Madrid: la pintura del remate es mediana. Los adornos de arquitectura de dicha Iglesia, entrando la portada, no tienen cosa que deba detenernos. Nuevamente ha costeado la Reyna, nuestra señora, un altar de bellas piedras, al lado del Evangelio, y la pintura de San Julián, que hay en él es de Don Mariano Maella». A mitad del siglo 
pasado este espacio pasó a llamarse plaza de Leganitos para acabar desapareciendo cuando toda esta parte de Madrid se igualó para crear la Plaza de España.

\section{EL MÉDICO A PALOS}

Acto II, Escena V.

Comedia de tres actos.

Litografiada por Juan Antonio López.

Comedia estrenada en Barcelona el cinco de diciembre de 1814, por la Compañia Cómica de esta ciudad. Tras la batalla de Los Arapiles, ocurrida el 10 de agosto de 1812 y ganada por las tropas españolas, Moratín se ve en la necesidad de huir de Madrid, siguiendo a las tropas invasoras. Primero pasará a Valencia, luego a Peñíscola, donde tras su enfrentamiento con el gobernador de la plaza, el general Elío, ardiente absolutista, fue embarcado en un buque rumbo a Francia a principios del año siguiente, 1813 , acusado de afrancesado. Pero aprovechando una escala técnica en Barcelona y su amistad con el general barón de Eroles, el literato logró quedarse en la ciudad condal en espera de saber la resolución del juicio de purificación que se se estaba celebrando en Madrid. Por fin, el trece de octubre de 1814 se publicó la resolución que eximía a Moratín de la acusación de colaborador del gobierno intruso.

A pesar de haber declarado en el prólogo de su anterior obra - La Escuela de Maridos-su intención de no volver a escribir ninguna nueva comedia, parece ser que no pudo resistirse a los ruegos del actor cómico Felipe Blanco que le pidió, hasta que obtuvo, un libreto en el que pudiera desarrollar al máximo todo su arte "de gracioso". $Y$ de nuevo Moratín echó mano del gran Molière para volver a repetir el experimentos que años atrás había realizado en Madrid, pero esta vez con "Le Médecin Malgré Lui». Al igual que ocurrió con el original, la adaptación y puesta en escena constituyó un gran éxito. Junto a Blanco, en el papel del sufrido campesino Sganarelle, en español Bartolo, trabajaron Vicente Alfonso y Bárbara Fort en los personajes principales.

Nos encontramos, al igual que en el ejemplo anterior, no ante una simple traducción de un texto, sino ante la genial adaptación de una obra, eliminando y añadiendo todos aquellos aspectos y detalles que más podían influir en el ánimo del espectador hispano. Entre los rasgos más importantes merece la pena destacar la simplificción que Moratín hizo del texto, eliminando hasta tres personajes y algunas escenas de los actos «para no interrumpir la fábula con distracciones meramente episódicas, sujetándose 


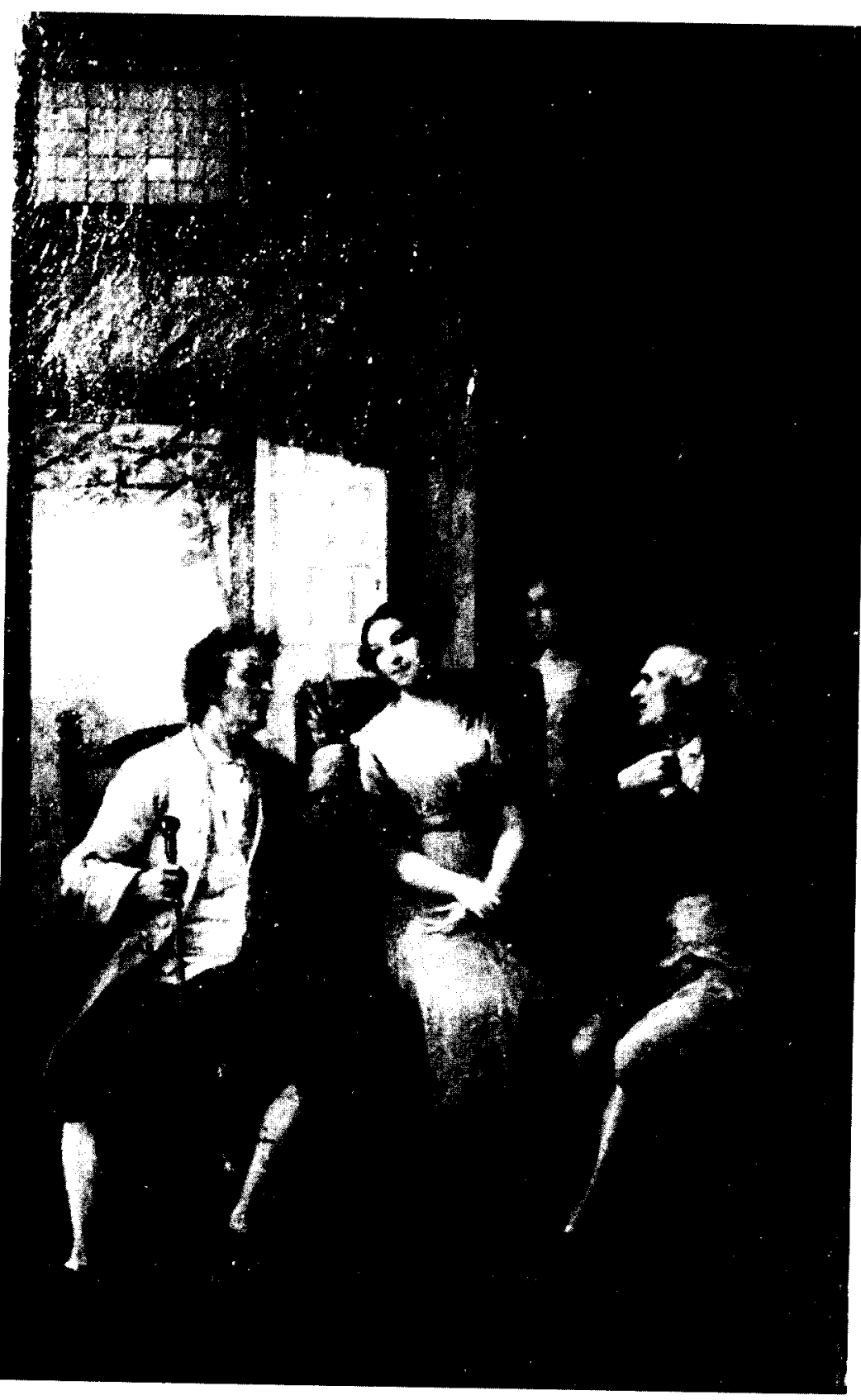


a la estrecha economía que pide el arte: sin la cual, a fuerza de ornatos viciosos, se entorpece la profesión dramática y se debilita el interés". De esta forma, nuestro pobre leñador sólo necesitará tres palizas para ser convencido por sus apaleadores de sus artes curativas, y dejará a un lado sus devaneos amorosos con la nodriza Jacqueline, que en el texto español se transforma en Andrea, una simple criada de la casa sin gran protagonismo.

La meta fue crear una comedia mucho más real, eliminando todas las malas expresiones y situaciones engorrosas que dentro de la mentalidad didáctica de un hombre de la llustración como era Moratín, no debían presentarse ante un auditorio "decente". El texto de Molière perdió toda su fuerza satírica al tiempo que los personajes dejaron de ser caricaturas burlonas de la realidad para convertirse en un cuento moralizante al gusto del momento. Sin lugar a dudas ambos autores tuvieron que beber de las mismas fuentes, puesto que el argumento constituía el tema de un cuento popular en aquel entonces que había ya originado diferentes fábulas como "El Médico de Bray" o "El Médico Campesino". Pero en el caso francés, Molière sólo quiso hacer una farsa llena de ingeniosa y original comicidad sin ningún tipo de moral o lección aplicable a la vida corriente, todo lo contrario al resultado de ia versión española.

El cuadro de Gálvez está inspirado en la escena quinta del segundo acto. Nos presenta el primer reconocimiento que Bartolo, en su papel de supuesto médico, hace de la enferma, la joven doña Paula, ante la atenta mirada de su padre, don Jerónimo, y los criados de la casa. En primer plano vemos, en el centro de la composición, a la joven sentada en una poltrona entre el fingido galeno y su progenitor, con las manos cruzadas $y$ la cara divertida. Bartolo, sentado en una silla, viste una elegante casaca de corte antiguo y un sombrero de tres picos que ha dejado caer en el suelo como corresponde a un médico. Con gesto decidido golpea su bastón y levanta su mano izquierda para dar mayor fuerza a sus palabras que parecen embelesar al anciano, también sentado, que le escucha, con ambas manos apoyadas en su bastón. La acción, siguiendo las indicaciones de la comedia, tiene lugar en el interior de una casa con una amplia puerta al fondo.

\section{CONCLUSIONES}

Al principio del cuarto tomo se consideró oportuno incluir una breve esplicación de las estampas presentadas al inicio de cada obra. Tras aclarar el asunto representado también se decía el autor y litógrafo de 
cada una de las ilustraciones. Con estas noticias se completaba la información ofrecida al principio del primer volumen donde se explicaba el pensamiento de la portada y se anunciaba su autoría: "Los dibujos de las estampas que acompañan a esta colección, son de los más acreditados profesores, entre los cuales se cuentan los pintores de Cámara don Vicente López y don José de Madrazo, que han querido contribuir gratuitamente con sus talentos a engalanar la edición y hacerla más digna del Público". Al no decir nada de Gálvez y Ribelles, se da por entendido que ellos sí tuvieron que cobrar la ejecución de sus cuadros para la presente edición.

Por motivos que desconocemos, el artista decidió entregar los cuatro lienzos a doña María Cristina de Borbón, ese mismo año 1831, aún siendo Reina Consorte, como el mismo Gálvez especificó en su Hoja de Servicios; aunque sin especificar si fue o no un regalo. Los cuadros formaron parte de los bienes personales de esta Reina, pues no aparecen mencionados en la Testamentaría del Rey Fernando VII, y en una fecha no determinada se los entregó a su segunda hija, la Infanta doña María Luisa Fernanda, Duquesa de Montpensier, que los instaló en su casa sevillana, el Palacio de San Telmo. De esta forma la serie pasó a la Condesa de París, siendo heredados por la Infanta doña María Luisa de Orleans, hasta terminar en manos de doña Dolores Borbón-Sicilia.

\section{BIBLIOGRAFIA SOBRE LEANDRO FERNÁNDEZ DE MORATÍN}

Ediciones en lengua española de las comedias de Leandro Fernández de Moratín:

1825: Obras dramáticas y líricas de D. Leandro Fernández de Moratín, entre los Árcades de Roma, Inarcio Celenio. Única edición reconocida por el autor. París, edición de Augusto Bobée, 1825, 3 tomos.

1830-31: Obras de D. Leandro Fernández de Moratín, dadas a luz por la Real Academia de la Historia. Madrid, edición de aguado, 1830-31, 4 tomos en 6 .

1846-48?: Obras de Don Nicolás y Don Leandro Fernández de Moratín. BIBLIOTECA DE AUTORES ESPAÑOLES. Madrid, edición de Rivadeneyra, 1848?

1867-68: Obras póstumas de D. Leandro Fernández de Moratín, publicadas de orden y expensas del Gobierno de S.M. Madrid, edición de Rivadeneyra, 1867-68, 3 tomos.

1884: Comedias escogidas. Barcelona, edición de Daniel Cortezo.

1924: Teatro. Clásicos Castellanos, número 58. Madrid, edición de Ruiz Morcuende, 1924.

1968: La Comedia Nueva. El si de las niñas. Madrid, 1968. Ediciones, introducciones y notas de John Dowling y René Andioc.

Documentación de Juan Gálvez:

Archivo General de Palacio:

Gracias al Expediente Personal que existe de Gálvez en el Archivo General del Palacio Real de Madrid (Caja 386, Número 19), es posible saber todos los trabajos que realizó para la Real Casa y su cronología. Además de las obras referidas, hay que señalar las siguientes: 
1817: "En el año 17 fue nombrado para pintar un techo en el nuevo Casino de la Reina y varios dibujos que le encargaron para adornos del mismo Casino".

“Para el mismo año tuvo Orden de pintar dos falúas que se construyeron en el Real Sitio del Retiro, para embarcarse SS.MM. en el estanque de aquel Sitio, las que fueron ricamente adornadas".

«En el mismo año se le encargó el diseño y dibujo de un velador que se ejecutó en bronce para la Pieza Octogonal del mismo Casino de la Reina".

"En el mismo tuvo Orden de pintar una carretela para SS.MM.».

«En el mismo año tuvo Orden para pintar dos piezas de verdura en el entresuelo del Palacio para pajareras de S.M. la Reina".

1818: "En el 18 pintó de Orden de S.M. dos cuadros al oleo del retrato del Rey con el manto del Toyson".

"En aquel tiempo fue encargao de hacer los dibujos de la cuna y envoltorios para la primera sucesión de SS.MM.".

"Posteriormente volvió al Casino para pintar el techo del Gabinete Octógono".

"Enseguida pintó el techo de la Pieza Comedor".

1819: "En el año 19 volvió a pintar en el mismo casino, la bóveda de la Pieza Rústica, y las dos piezas que la anteceden".

1820: "En el 20 pintó la gran pieza estufa, en la que figura una tienda de campaña con diferentes vistas".

"En este mismo año obtuvo el nombramiento de S.M. de Teniente Director de la Real Academia de San Fernando por consulta de la misma".

1822: “En el 22 limpió y restauró todos los techos del transcuarto de S.M. la Reina en el Real Palacio de Madrid".

1825: «En el 1825 tuvo Orden de S.M. para pasar al Real Sitio del Pardo, a pintar en aquel Palacio, dando principio con la bóveda del Salón de Embajadores, que tiene 77 y $1 / 2$ pies" "Enseguida pasó de Orden de S.M. al Real Sitio de San Lorenzo a pintar en aquel Palacio el techo de la Pieza de Dormitorio de S.M.".

"Concluida que fue esta obra regresó al Pardo, a continuar sus trabajos, pintando al fresco la bóveda de la Pieza de Retrete en la habitación del Rey".

1826: «En el 26 volvió al Escorial a pintar un techo de la pieza de Despacho de S.M. en aquel Palacio".

"Coricluido que fue este trabajo volvió al Pardo a pintar en aquel Palacio, una bóveda que media a las habitaciones de SS.MM.".

"En este mismo año le nombró S.M. Director de la Real Academia de San Fernando, por consulta de la misma".

1827: «En el 27 pasó nuevamente al Pardo a pintar al fresco la bóveda de la Escalera Principal de aquel Palacio".

"En el mismo año tuvo orden de S.M. para pintar un techo en la pieza de Despacho del Señor don Carlos".

“En el mismo año pintó el techo del Salón a donde S.M. dá la Corte».

1828: "En el 28 volvió al Pardo a pintar nuevamente la bóveda de la Pieza de Retrete, en razón de haber variado la forma que tenia y sus adornos".

"En el 28 tuvo orden de pintar el techo de la pieza que antecede a la del Despacho de S.M. en el Real Palacio de Madrid".

"En el mismo año tuvo orden para hacer los dibujos de candeleros y cruz para la Real Capilla del Palacio de Madrid, con las plantas y cortes correspondientes para su construcción".

"En el mismo volvió a limpiar y restaurar los techos del trascuarto de S.M. la Reina".

1829: "En el 29 volvió a hacer otros muchos dibujos de otro juego de candeleros para la misma Real Capilla».

1830: “En el año 30 tuvo orden de pintar dos techos en el Palacio de Madrid en la Pieza de Dormitorio de SS.MM.».

1831: "En el 31 hizo un dibujo para un velador del gusto gótico para ejecutarlo en bronce".

1832: «En el 32 por Real Orden pasó al Sitio de San lldefonso a pintar en el Real Palacio en la nueva habitación de S.M. la Reina doña Isabel II en la que pintó siete bóvedas ricamente adornadas y también restauró el techo de Retrete por haber padecido en razón de las obras que se hizo en el mismo". 
También se mencionan la relación algunos servicios extraordinarios:

1831: «En el año 31 presentó a S.M. la Reina Gobernadora cuatro cuadros pequeños, asunto de las Comedias que escribió D. Leandro Martín, a saber, "La mogigata", "El sí de las niñas", "La escuela de los maridos" y "El médico a palos". En el año 1832 le encargó la Reina Gobernadora la formación de los dibujos para una capilla del gusto gótico para la Posesión de Quita Pesares, propia de S.M.".

«En el mismo tiempo también fue encargado de hacer varios dibujos de Lámparas, Custodia, Cáliz, Candeleros, Cruz y demás para el servicio del Altar en Misa Pontifical, todo del orden Gótico quedando a su cargo la Dirección de la misma Real Capilla, habiendo estado ocupado en estos trabajos desde el 15 de noviembre del mismo año hasta el 24 de julio del año 34 en que por resolución de S.M. quedaron suspendidos los trabajos de dicha obra".

\section{BIBLIOGRAFIA SOBRE JUAN GÁLVEZ}

Alegre y Nuñez, L.: Catálogo de Calcografia Nacional. Madrid, 1968, núm. 209.

BANDA Y VARGAS, A. de la: "La Colección pictórica de la Infanta Luisa de Orleans", en ANALES DE LA UNIVERSIDAD HISPALENSE, Sevilla, vol. XVIII, 1957-1958, tomo I, págs. 34-57. "Juan de Gálvez pintor de estampas moratinianas", en ANALES DE LA UNIVERSIDAD HISPALENSE, vol. XXIII, Sevilla, 1963, págs. 55-59.

BARCıA, A.M.: Catálogo de los retratos de personajes españoles que se conservan en la sección de estampas de la Biblioteca Nacional. Madrid, 1901, núm. 874.

Carrete Parrondo, J. y otros: Catálogo del Gabinete de Estampas del Museo Municipal de Madrid. Madrid, 1985 , Tomo I, núms. $7-20$ y 29 , pág. 32 y 35 y 26-7, 8, 9, 10, 11 y 12 , págs. 89-90. Catálogo general de Calcografía Nacional. Madrid, 1987, núm. 752-757.

CASTANNEDA, D.: Vicente López Portaña, ilustrador del libro. Madrid, 1943.

Catálogos de exposición:

1866: Catálogo de los Cuadros y Esculturas pertenecientes a la Galería de SS.AA.RR. Ios Serenisimos Señores Infantes de España, Duques de Montpensier. Sevilla, 1866, págs. 5657. Núms. 238 al 241.

1981: Estampas. Cinco Siglos de Imagen Impresa. Madrid, Biblioteca Nacional, 1981, núm. 421 y 422 , pág. 114 y núm. 432, pág. 115.

1996: Estampas de la Guerra de la Independencia. Misera humanidad, la culpa es tuya. Madrid, Museo Municipal, 1996, núm. 132-135, págs. 213-215.

1996: Francisco de Goya y la estampa de su época. Madrid, Real Academia de Bellas Artes de San Fernando, 1996, págs. 28 y 34.

CaVEDA, J.: Historia de la Real Academia de San Fernando. Tomo II, Capitulo V.: "La pintura en los últimos años del reinado de Fernando VII y los primeros de Isabel II». Madrid, 1867, tomo II, págs. 110 y ss.

Contento Marouez, R.: Juan Gálvez. Tesis Doctoral inédita leida en la Unviersidad Complutense de Madrid. Agradezco al autor la información que me facilitó sobre la génesis de este encargo al igual que la importante noticia de la próxima publicación de un libro sobre la vida de este pintor acompañado por un catálogo crítico de su obra.

Gaya-Nuño: Arte del siglo xIX. ARS HISPANIAE. Tomo XIX Madrid, 1966, pág. 105.

Junquera Mato, J.J.: La Decoración y el mobiliario de los Palacios de Carlos IV. Madrid, 1979.

Martinez Cuesta, Juan: "Juan Gálvez", en Painting in Spain in the Age of Enlightenment. Goya and his Contemporaries. Catálogo de la exposición celebrada en Indianápolis. New York, 1996, págs. 281-283.

NAvascuez, P.: "La Alameda de Osuna: Una villa suburbana", en ESTUDIOS PRO ARTE. Madrid, 1975.

Ossorio y Bernard, M.: Galeria biográfica de Artistas Españoles del siglo xix. Madrid, 1883, pág. 268.

Pardo Canalis, E.: “Una sesión de las Cortes de Cádiz por Gálvez», en GOYA, 1967, núm. 79, pág. 57.

"Otra estampa histórica de Juan Gálvez", en GOYA, 1968, núm. 80, pág. 130. 
Revero y Miaeira Faeixa, C.: Pintura y Escultura en España, 1800-1910. Madrid, 1995, págs. $29,59,65,468$ (1)-18-.

Sal A VALDES, M.: Album de los sitios de Zaragoza, láminas dibujadas y grabadas por D. Juan Gálvez y D. Fernando Brambila. Zaragoza, 1905. Prólogo de Sala Valdés.

SENTENACH, N.: "La pintura en Madrid", en BOLETÍN DE LA SOCIEDAD ESPAÑOLA DE EXCURSIONISTAS, 1907, pág. 235.

THIEME-BECKER: Küntier-Lexikon, tomo XIII, págs. 135-6.

VEGA, J.: Orígen de la litografía en España. El Real Establecimiento Litográfico. Madrid, 1990, págs. 314-356.

Museo del Prado. Catálogo de Estampas. Madrid, 1992, núm. 1.193 al 1.202, págs. 235237.

Velásco AguirRe, M.: Catálogo de grabados de la Biblioteca de Palacio. Madrid, 1934, núm. 34, págs. 19-21.

VIZANA, Conde de: Adiciones al diccionario histórico... Madrid, 1889, tomo II, págs, 215-217. 
